\title{
IMPROVING ACCESS TO QUALITY CLINICAL NURSE TEACHING - A PARTNERSHIP BETWEEN AUSTRALIA AND VIETNAM
}

\section{T. Harvey ${ }^{1}$, P. Calleja ${ }^{1,}$ D. Phan Thi $^{2}$}

Corresponding author:

${ }^{1}$ Theresa Harvey RN MN FRCNA

Lecturer, School of Nursing and Midwifery

Queensland University of Technology

Victoria Park Road, Kelvin Grove Queensland.4059 Australia

Ph: +617 31385951 Email: tm.harvey@qut.edu.au

${ }^{1}$ Pauline Calleja RN MN MRCNA

Lecturer, School of Nursing and Midwifery

Queensland University of Technology

Victoria Park Road, Kelvin Grove Queensland.4059 Australia

Ph: +617 31389607 Email: pauline.calleja@qut.edu.au

\author{
${ }^{2}$ Phan Thi Dzung BA \\ Chief of Nursing Department \\ Viet Duc University Hospital \\ 40 Trang Thi Street \\ Hanoi - Vietnam \\ Ph:+84438255912Email:phanthidung2003@yahoo.com
}




\title{
IMPROVING ACCESS TO QUALITY CLINICAL NURSE TEACHING - A PARTNERSHIP BETWEEN AUSTRALIA AND VIETNAM
}

\begin{abstract}
Until recently, standards to guide nursing education and practice in Vietnam were nonexistent. This paper describes the development and implementation of a clinical teaching capacity building project piloted in Hanoi, Vietnam. The project was part of a multicomponent capacity building program designed to improve nurse education in Vietnam. Objectives of the project were to develop a collaborative clinically-based teaching model that encourages evidence-based, student-centred clinical learning. The model incorporated strategies to promote development of nursing practice to meet national competency standards.
\end{abstract}

Thirty nurse teachers from two organisations in Hanoi participated in the program. These participants attended three workshops, and completed applied assessments, where participants implemented concepts from each workshop. The assessment tasks were planning, implementing and evaluating clinical teaching. On completion of the workshops, twenty participants undertook a study tour in Australia to refine the teaching model and develop an action plan for model implementation in both organisations, with an aim to disseminate the model across Vietnam.

Significant changes accredited to this project have been noted on an individual and organisational level. Dissemination of this clinical teaching model has commenced in Ho Chi Minh, with further plans for more in-depth dissemination to occur throughout the country.

Keywords: Nurse teaching, Vietnam, clinical teaching, teaching models 


\section{INTRODUCTION - CONCEPT FOR THIS PARTNERSHIP PROGRAM}

In 2010, the Vietnam Nursing Association (VNA) with the support of the Vietnam Ministry of Health $(\mathrm{MoH})$ endorsed their national nursing competency standards. The Queensland University of Technology (QUT) has been working with the VNA in selected universities and medical schools in Vietnam to support implementation of nursing curricula, based on these competency standards (Chapman et al 2011, Lewis, Van \& Gray 2011). As the quality of clinical education was identified as a significant barrier to developing the nursing profession in Vietnam, a team of nurse leaders from QUT conceptualised a project to train future clinical nurse leaders in Vietnam. This project was funded by the Australian Agency for International Development (AusAID in 2008-09) and QUT, in conjunction with the Vietnam MoH, Viet Duc University Hospital (VDUH) Hanoi and the Department of Fundamental Nursing at Hanoi Medical College (HMC). The project was titled "Strengthening nurse led institutional capacity for in-service education and clinical teaching".

The aim of this project was to develop and pilot a program that created a model of collaborative and sustainable clinical teaching. Specifically the focus was on promoting clinical education strategies that supported the development of nursing practice that met the new nationally endorsed nurse competency standards. Expected outcomes of the project were to create a nursing education environment that encouraged evidence-based, studentcentred clinical learning to meet international standards of education which could be disseminated throughout Vietnam.

The purpose of this paper is to describe the processes involved in establishing a program and the educational approaches which informed its development. The paper also provides some preliminary reflections of factors which influenced the implementation and outcomes of the program. 


\subsection{Background and History of Nursing in Vietnam}

During the many years of war (from 1955 - 1975), Vietnam's health system developed in response to first aid and emergency care needs, with nursing carried out by people trained in basic first aid (Jones, O'Toole et al. 2000). The end of the war in 1975 marked the shift of focus by the Vietnamese Government from a basic care approach to one which aimed to provide comprehensive health care to their growing population (Crow and Thuc 2011). This required rapid production and training of health care personnel.

The effect of this rapid growth resulted in multiple levels of education for nurses, which varied from brief certificate/vocational training following secondary school, to four year bachelor programs. Regardless of the education received, all nursing graduates work at the same level and scope in the clinical environment, contributing to variable standards in patient care and overall confusion and discontent within the nursing profession (Muc 2009) Adding to this confusion is that the majority of nursing schools, universities and hospitals work in isolation from each other, which increases fragmentation of nursing in the healthcare system.

Improving the quality of nursing care has been identified as a key to improving essential healthcare services in Vietnam (Xuan Do Dinh 2010). However, prior to 1990, there were no national standards or regulation of nurses in Vietnam and nurses worked within a complex bureaucratic system under the domain of the MoH. In 1990, the Vietnam Nurses Association (VNA) was established with the aim of improving the quality of patient care and standardisation of nursing practice (Jones, O'Toole et al. 2000; Stockhausen 2007). In 2006 the Vietnamese Government committed to recognition of healthcare licenses (including nursing) by 2016 (Van, Quoc et al. 2010). 


\subsection{Barriers for adequate standardisation of professional nursing in Vietnam}

The historical, social, political and economic context in Vietnam has presented numerous challenges to the development of nursing as a profession. Lack of standardisation of nursing education following the war has contributed to the failure of nursing education to meet national or international competency standards (Van, Quoc et al. 2010; Crow and Thuc 2011). Additionally, nurses had limited opportunities to develop clinical teaching skills necessary to attain international standards (Kristy 1995; Jones, O'Toole et al. 2000). Historically, the majority of colleges and universities who provide nursing education are run by physicians. Physicians as educators typically focus on medical management of diseases rather than a nursing care view point of education (Stockhausen 2007).

Vietnamese nurses are striving for professional recognition, with nurse education seen as being at the forefront of improving standards of care, patient outcomes and nursing autonomy (Pron, Zygmont et al. 2008). There is limited published literature regarding nursing education in Vietnam. However, during meetings between our team and representatives of the Vietnam $\mathrm{MoH}$, the $\mathrm{MoH}$ representatives noted many problems existed once nurses graduated from their training. These problems included issues with adequate supervision and support of new graduates and limited evidence of the impact of changes to undergraduate nurse education on graduate's nursing practice. Poor communication between education providers and health care agencies was also recognised as a significant problem. The $\mathrm{MoH}$ also noted that technical nursing care is often not centred on patient and family needs.

To rectify these barriers, the $\mathrm{MoH}$ identified the need to strengthen capacity of in-service clinical education for nurses. Such capacity building would support implementation of Vietnam's recently endorsed national nurse competency standards. Three specific areas of care were subsequently identified that needed urgent improvement, infection control, wound care and communication. 


\section{METHODOLOGY I THEORETICAL UNDERPINNINGS}

\subsection{Needs assessment and Program overview}

In developing the clinical education capacity building program, the QUT team consulted with the $\mathrm{MoH}$, hospital and college representatives to identify specific needs and to ensure the overall concept of the program was contextually relevant. Shared goals and explicit expectations of all contributors to an international partnership were vital to the success of the project outcomes (Fitzpatrick 2002). It was identified that another important outcome of the program was to assist participants improve their English. This was because most international nursing research and evidence based practice literature is in English, and thus improving English would enable the utilisation of this information to improve patient care.

The program entailed three five-day workshops over a five month period, conducted face to face in Hanoi. Three hospital wards were chosen to be part of the program as pilot areas of change (Hepatobiliary, Renal and Perioperative care). The participants were selected from applicants from Viet Duc University Hospital and Hanoi Medical College. A mix of participants from the hospital and college was integral to the objective of introducing the concept and development of collegial relationships, so that organisations worked collaboratively and formed partnerships. On completion of the three workshops, twenty participants were invited to attend an intensive two week study tour in Brisbane, Australia. 


\subsection{Pedagogical underpinnings}

Active learning or student centred learning pedagogy was used as the underpinning methodology for this program as it enhances learning and can lead directly to improved educational outcomes. This was complemented by utilising the principles of adult learning theory, role modelling and action learning. Active learning represents a model of teaching that has minimal teacher lecturing and multiple small group activities (Steiner and Snell 1999). As most health professionals in Vietnam are educated using didactic methods only (Hirst, Jeffery et al. 2009), active involvement was important to promote increased attention, motivation, memory, and promote higher order thinking and mutual teacher/learner feedback (Steiner and Snell 1999).

Action learning was also employed as it uses the experiences and needs of the learners, rather than the knowledge of the teacher as the working material (McGill and Brockbank 2004). To create long-term change, ownership must be an integral aspect of the strategies used (Kotter 1995). This was important to ensure that the program was contextually relevant for their health care system in Vietnam. Participants needed to understand the principles of clinical teaching, but primarily be able to adapt new knowledge and processes to their local context. Consistent with the tenants of change theory described by Lewin (Lewin 1958), our vision was for the participants to be active in the development of their own clinical education model appropriate for their context. 


\subsection{Conceptual Framework}

\subsubsection{Program Development}

The objectives of the project were to

1) develop clinical nurses and nurse teachers' capacity and ability to teach others,

2) produce self-directed learning packages and course materials for ongoing use.

3) develop an action plan for dissemination of the clinical teaching model throughout Vietnam

Once a working knowledge of the social and nursing background in Vietnam was acquired, a concept map was developed for the program (Fig 1.). This was the starting point to visualise how the program would be conducted and the overall topics that needed to be interwoven. The application of this concept was refined after each workshop with feedback from participants. Thus an action learning approach to developing the program was enacted, enabling the development of materials that better suited the context and needs of the nurses and nurse teachers in Vietnam. The process known as Assess, Plan, Implement and Evaluate (APIE) was selected as the conceptual framework for teaching and learning, as this is a well known decision making process, and is often referred to as a continuous improvement cycle (Emerson 2007). Using this framework the content of the workshops in Hanoi was divided into three modules as:

1) Needs Assessment

2) Planning and Implementation

3) Assessment of learning and Evaluation of teaching. 
Figure 1 - Concept map - Strengthening nurse led institutional capacity for in-service education and clinical teaching in Hanoi, Vietnam
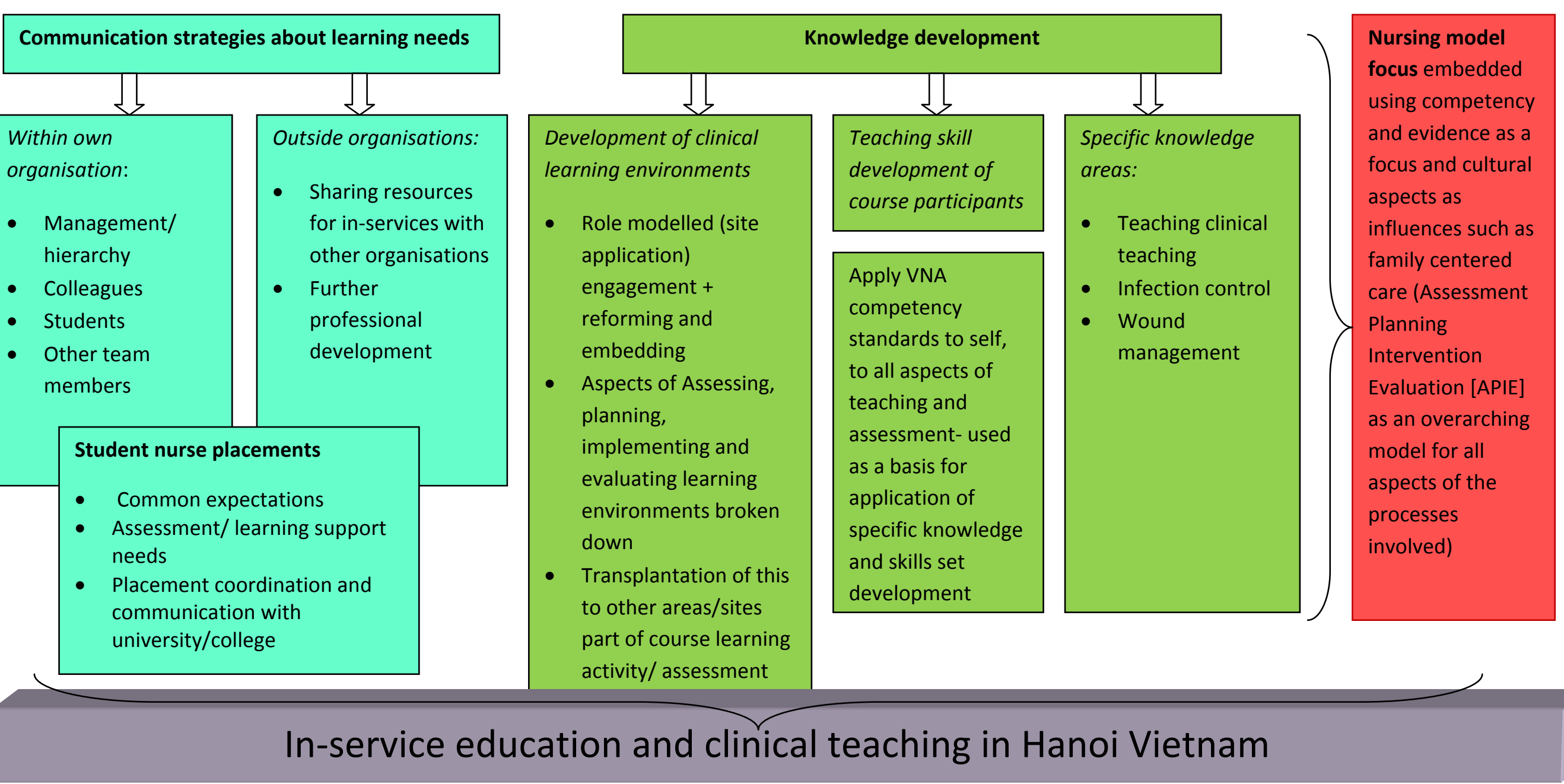

\section{In-service education and clinical teaching in Hanoi Vietnam}


Between each of the workshops, the participants were encouraged to use the self directed learning packages to complete an assessment item based on the information covered. Each assessment item was applied to the hospital environment. Table 1 displays the learning outcomes for the three workshops of the program

TABLE 1 LEARNING OUTCOMES FOR THE THREE WORKSHOPS OF THE PROGRAM

\section{The overall learning outcomes for the program}

1. To improve communication about nurses and nursing students' learning needs between health agencies and health care providers;

2. Select relevant Nursing Competencies for Nurses in Vietnam and strategies to aid in planning and managing educational experiences;

3. Assist in developing clinical learning environments to improve patient and family centred, holistic care;

4. Apply principles of teaching and learning in a variety of contexts to ensure effective clinical teaching methods;

5. Effective infection control and wound management and;

6. Critically analyse research literature to ensure nursing models of care are competency and evidence-based

7. Improvement of English language skills of the participants?

\subsubsection{Program Overview}

The new Vietnam Nursing Competency Standards were discussed and utilised throughout each stage, to highlight the minimal care requirement that shapes education and assessment in nursing. Assessment of a work environment for the purpose of planning, education and using underlying evidence from the literature was pivotal to the whole program.

Teaching was conducted at Viet Duc University Hospital, which allowed us to carry out 'ward based activities' during each workshop. The classroom was set up with two screens and two projectors, one for English slides and the second for Vietnamese interpreted slides. The participants chosen to attend the program had diverse levels of clinical or educational 
experience and English language skills. While participants were undertaking English lessons at the hospital in their own time, translation was required for most of the presentations. As the presenters, we needed to carefully select our explanations for new concepts (e.g. critical thinking) as over-explaining appeared to increase confusion. However we found that using relevant clinical examples assisted participants to grasp and understand new concepts that were being explored.

We took into consideration the average attention span for adult learners is around $15-20$ minutes (Emerson 2007). As the presentations included listening to another language and then to translation, this can further reduce the ability of the participants to focus for long periods of time. Hence a change of pace and activities were strategically implemented throughout the workshop. These included working in pairs, small groups, games and quizzes, contextual clinical scenarios, ward observation, handouts to influence and guide note-taking and structured discussion. Our strategies also included providing translated PowerPoint presentations, role play and visual resources.

\subsubsection{Workshop 1: Module 1- Assessment}

Table 2 shows content topics presented in workshop one. The hospital 'ward activity' for this teaching period was based on action learning, the group was divided into three and allocated to one of the selected wards. This activity involved observation of nursing care, where participants stood back and watched how the nurses in these areas performed their duties, supported by an observation tool and QUT lecturers. Participants were instructed to concentrate on the selected issues of wound care, infection control and communication. On returning to the classroom, the participants discussed the nursing practice witnessed. This formed the basis of the first assessment piece, a training needs analysis. A training needs analysis is a "training and educational strategy that meets the continuing professional needs of healthcare staff, both qualified and unqualified" (Quinn and Hughes 2007 ). Each 
participant selected an identified issue and then completed an analysis of this issue. This enabled them to discover exactly what was needed and if education was required to address the identified issue.

Group work within the classroom setting was challenging. At first all participants were grouped according to their organisation and specialty area. We quickly recognised the need to intervene to ensure allocated groups included a mixture of hospital and college staff from different nursing specialities, to facilitate collegiality. To assist the participants between workshops with their assessment piece, they were provided with a template and online support via email and Skype was provided. Participants were also allocated to a small 'support group' who were encouraged to meet between workshops to discuss how they were progressing with their assessment piece. Again these groups had a mix of college and hospital participants. This collegiality was further enhanced through several recreational activities, giving participants the opportunity to practice their English (with us) and develop social relationships with work colleagues. We found as the program continued and participants worked together, they began to see the value of each other's diversity and less intervention was required to mix groups from the different organisations.

TABLE 2: WORKSHOP 1- MODULE 1: ASSESSMENT

\section{LEARNING OUTCOMES TOPICS COVERED}

- Discuss the theories and principles of adult learning and adult learning styles.

- Demonstrate knowledge of critical thinking within nursing practice and education process.

- Discuss overall teaching
- Adult learning

- Learning styles

- Critical thinking and nursing practice

- APIE (assess/plan/implement/evaluate)

- Assessment of principles (needs assessment)

- Dimensions of competency

- the clinical learning environment
ASSESSMENT FOR MODULE 1
Undertake training needs analyses for a particular ward and problem identified by staff on the ward. Report results - submit via email to QUT lecturers 
and learning process.

- Demonstrate knowledge of and apply assessment principles for clinical teaching related to education, wound care and infection control.
- communication

- nursing competencies

- training needs analysis (TNA)

- clinical ward activity training needs analysis example, supported by

Australian teachers

\subsubsection{Workshop 2: Module 2- Planning and Implementation}

Table 3 shows content topics presented in workshop 2. Role modelling was used extensively in workshop 2 to display teaching principles participants were learning and to uncover how the process of APIE is cyclical. We commenced workshop two with a summary of participant feedback from workshop one and how we had incorporated this into developing workshop 2. As this workshop included 'teaching methods' in implementation, we modelled as many as possible within our own teaching of the content, providing an experiential model of learning (pointing these out to participants as we went). Towards the end of the workshop, each participant had an opportunity to practice one or two techniques by presenting a seven minute teaching session on a non-nursing topic. This enabled them to be involved in the concepts underpinning learning and teaching rather than focussing on nursing content. Feedback for each participant was given by the group so that all participants played an active role at all times.

The hospital 'ward activity' during this workshop focused on communication. Effective communication in the health care industry is necessary and a high priority in the delivery of safe, quality care (WHO 2007). The ward learning activity was based on a questionnaire that each participant had to implement, asking a patient, a nurse and a patient's relative, similar questions about communication from their perspective. This activity highlighted to the participants where the problems in communication were occurring and the implications of this for developing their teaching packages. 
The assessment following workshop 2 required participants to develop a teaching plan for their identified problem which was explored in their training needs analysis. This assessment activity allowed participants to see how critical links needed to be made and facilitated understanding of the need for the root cause of problems to be addressed as the focus of teaching and learning. Using evidence as a basis for planning and implementing education was an important factor in helping participants understand how and when education can assist in improving performance and its limitations. For example if lack of resources was the root cause of a problem, then education will have limited effects on improving delivery of care.

TABLE 3 WORKSHOP 2: MODULE 2- PLANNING AND IMPLEMENTATION

\section{LEARNING OUTCOMES}

- Discuss the principles of planning and designing education programs for addressing a performance need

- Demonstrate knowledge of application of the teaching process

- Formulate and apply learning outcomes to education session design

- Demonstrate knowledge and application of communication skills for education purposes (for both ward nurses and student nurses)

- Demonstrate and apply knowledge of teaching strategies for clinical education

- Discuss and identify resources required to

TOPICS COVERED

- The clinical teacher

- The teaching process

- Learning outcomes

- Facilitating learning in the clinical setting

- Communication

- Teaching method choice

- Deep vs surface learning

- Demonstrated teaching methods

Participants demonstrate teaching planning and implementation for nonnursing topic

- Clinical ward activitycommunication with patients, communication with colleagues

Apply TNA outcomes to start assessment two

\section{ASSESSMENT FOR MODULE 2}


carry out effective

teaching

- Introduce how planning

and evaluation of

teaching is linked

\subsubsection{Workshop 3}

Table 4 lists content topics presented in workshop 3, where participants were encouraged to apply the principles of assessment of learners to measure achievement of learning outcomes and evaluation of teaching. To understand how assessment is experienced and understood in the clinical environment, we commenced again with a ward activity. Each participant interviewed a nurse about their experience of assessment and then collated findings with the larger group.

During this workshop the participants completed their teaching plans by developing how they would assess their learners and the quality of their own teaching. For the assessment of this last workshop participants were expected to implement their teaching plan and complete this process by evaluating learning and teaching. They were also required to write a report including what would be changed if the teaching was conducted again.

TABLE 4. WORKSHOP 3: MODULE 3 - ASSESSMENT AND EVALUATION

LEARNING OUTCOMES

- Discuss the principles of planning and designing assessment and evaluation for a teaching session that addresses a performance need.

- Demonstrate knowledge of conducting assessment and evaluation.
TOPICS COVERED

ASSESSMENT FOR MODULE 3

Finalise assessment for teaching plan, undertake teaching in the clinical environment and evaluate teaching. Write up results and recommendations for changes for future teaching. Include photographic evidence or evaluation of teaching in support to 
- Discuss issues and barriers related to assessment and evaluation in the clinical teaching setting.

- Apply principles of assessment and Evaluation to teaching
- Who is the assessor

- Factors and tips for dealing with poor performance

- Barriers to assessment

- Evaluation (of teaching / program)

- Evaluation instruments

- Clinical ward activity about types of assessments nurses have had and prefer

- Apply assessment principles to complete assessment two teaching plan illustrate teaching

undertaken. Submit via email. Final participants for $4^{\text {th }}$ workshop/study tour in Australia chosen from results of participants and quality of work so far

\subsubsection{Intensive two week study tour - Australia}

The three Hanoi workshops aimed to develop and pilot a teaching model that would be implemented throughout the hospital. To further assist in strengthening nurse led institutional capacity for in-service education and clinical teaching, a two week intensive tour of Australia was implemented. During this time participants were able to observe teaching in the university in clinical practice laboratories and classrooms. The program included presentations from key hospital and university personnel about clinical education and how clinical learning experiences are linked with the Australian nursing competency standards. A significant component of the program was visiting several hospital environments to witness firsthand how clinical education is managed in an Australian hospital. From these experiences we encouraged participants to deconstruct and relate their experiences to their existing education system in order for them to reconstruct 'new' knowledge and a workable plan. These activities facilitated the development of the action plan and its implementation in Vietnam.

An important goal of the program was to develop the selected participants to be change agents and create a 'Clinical Teaching Model' for Viet Duc University Hospital. It was 
intended that this model would eventually be disseminated throughout Vietnam. To guide this implementation phase, participants were asked to do a SWOT analysis. SWOT is an acronym for Strengths, Weaknesses, Opportunities and Threats (Piercy and Giles 1989). The main purpose of this analysis is to identify the strategies that will create a clear model that best aligns with an organisation's resources and capabilities. This exercise facilitated participants to forecast any barriers or changing trends and to include these predictions in their decision making process for their clinical teaching model.

TABLE 5 INTENSIVE STUDY TOUR: ACTION PLAN FOR 'CLINICAL TEACHING MODEL'

$\begin{array}{lll}\text { AUSTRALIAN INTENSIVE } & \text { TOPICS COVERED } & \text { DAILY ACTIVITY } \\ \text { STUDY TOUR OBJECTIVES } & & \text { OUTCOMES }\end{array}$

To observe clinical education processes that are used in Australia, specifically related to:

- Undergraduate clinical laboratory education

- Undergraduate students clinical practice education (in the hospital)

- Orientation of new staff (including mandatory training)

- Novice practitioner education for new graduates

- On-going life-long education for staff

- To identify resources, processes and issues that need to be addressed to support nursing in-service

- To develop a leadership model of in-service education for dissemination throughout Vietnam
- Overview of nurse teaching program delivered in Vietnam

- Different clinical teaching models (visiting presenters from public and private hospitals)

- Collegial communication to support student nurse education

- Ensuring undergraduate nursing programs are current and relevant

- Leadership for change

- Transition to practice
- Streamlined teaching plans and resources already developed into generic plans

- Draft letter / template from college to hospital

- Framework for inservice program

- The APIE revisited / modules / powerpoint presentations and activities 
- Daily outcome activity

- develop a flow chart

of communication

between education

system and hospitals

\section{OVERALL STUDY TOUR OUTCOME}

Action plan for further dissemination and development of clinical teaching at this hospital and college site with allocation of leaders and resources and time lines (used SWOT framework)

\section{REFLECTIONS ON EXPERIENCES}

The lessons learned during this project are numerous. We found that a range of administrative and cultural issues impacted on the ability and time needed to set up collaborative decision making across institutions and sectors. At times, outside processes (e.g. hospital audit) impacted on the participants' ability to participate in the onsite teaching program. Additionally, variation in the levels of education and English within the group, in terms of knowledge resulted in more time required to adopt unfamiliar concepts in a foreign language. The PowerPoint presentations were translated into Vietnamese for the three workshops held on site. Some of the translation was not correct or accurate and this was only communicated towards the end of the third workshop. This is because for many English words there is not an exact word in Vietnamese hence this caused some confusion, which we were not aware of in the beginning. For example the words "assessment" and "evaluation" are the same when translated into Vietnamese but can be referred to as two different concepts in English and were presented this way.

Initial monitoring of the effectiveness of training activities indicates that participants have demonstrated improvements in skills and knowledge as shown by: changes being made to time lines in their plans - an indication of confidence; changes in key issues and priorities; the keeping of statistics on rates of infection in the wards and the introduction of a more 
structured staff orientation program. The feedback from participants has demonstrated that there is more communication and more ideas being raised in relation to nursing students learning needs, which sets a new precedent and will inform processes for the future. In addition, many of the participants have now enrolled in a Distance Learning Program (part of QUT School of Nursing's AP Vietnam Capacity Building Project) to continue learning in relation to nurse education. This project has developed strong collaborative relationships between us (the lecturers), QUT staff and the head nurses (the leaders) from the counterpart organisations in Vietnam. With ongoing support and correspondence, the provision of future development opportunities in the area of leadership is already being planned.

\section{PROGRESS AND FUTURE DIRECTIONS OF CLINICAL NURSE EDUCATION IN}

\section{VIETNAM}

Thirty nurse teachers from VDU and HMC participated in the program, attending three workshops, and completing three assessment items. Once this platform had been set, twenty participants undertook a two week study tour in Brisbane, Australia. During this tour the clinical teaching model was refined and an action plan developed to integrate into both organisations with possible implementation across Vietnam. The participants in the study tour experienced clinical teaching and learning at QUT and were able to visit selected hospitals to experience clinical teaching in these settings. These learning points and skills were presented by participants back to their fellow colleagues who were not able to attend the study tour. At present there is significant planning underway to incorporate the clinical teaching model developed across the organisation and how this may be implemented in other regions. Effectiveness of the program was evaluated and measured throughout the implementation phase and in follow up visits to the clinical site. While a detailed review of the outcomes and evaluation of this program will be reported elsewhere, it should be noted that. from the participant's perspective one of the most significant outcomes has been the creation of a bridge between identified training needs and clinical practice. This development is assisting in building a solid foundation for nursing practice, supported by the new national 
nursing competencies, at VDUH. It will be an ongoing process to ascertain the sustainability of the action plan, but with ongoing support future development opportunities in the area of leadership are already being planned.

No conflicts of interest declared

\section{ACKNOWLEDGEMENTS}

This project was funded by a Public Sector Linkage Program of AusAID [Project ID: ROU 50464] titled " Strengthening nurse led Institutional capacity for in-service education and clinical teaching in Hanoi, Vietnam and Supported by Queensland University of Technology(QUT).

Particular acknowledgment is given to Professor Genevieve Gray, Scholar in Residence, Queensland University of Technology School of Nursing, for her leadership of this program as Director Capacity Building Program in Nurse Education in Vietnam 


\section{REFERENCES}

Chapman, H., Lewis, P.A., Osborne, Y., \& Gray, G. (2011) (in press). The Viet Nam teaching fellowship program: an action research approach to building capacity for leading and sustaining curriculum change. Nurse Education Today

Crow, G. and L. B. Thuc (2011). "Leading an international nursing partnership: the Vietnam nurse project." Nursing Administration Quarterly 35(3): 204-211.

Emerson , R. J. (2007). Nursing Education in the clinical setting. Missouri, Mosby Elsevier Health Sciences.

Fitzpatrick, J. J. (2002). "International Partnership for Research." Applied Nursing Research 15 (4): 199.

FM Quinn \& SJ Hughes (2007 ). "Quinn's principles and practices of nursing education (5th edn). Cheltenham, UK: Nelson Thornes ".

Hirst, J. E., H. E. Jeffery, et al. (2009). "Application of evidence-based teaching in maternal and child health in remote Vietnam." International Journal of Gynecology and Obstetrics 104(2): 152-155.

Jones, P. S., M. T. O'Toole, et al. (2000). "Empowerment of nursing as a socially significant profession in Vietnam." Journal of Nursing Scholarship 32(3): 317-321.

Kotter, J. (1995). "Leading Change:Why Transformation Efforts Fail." Harvard Business Review 73(2): 56-67.

Kristy, S. J. (1995). "Health issues in nursing in Vietnam." Holistic nursing practice $9(2): 83-90$.

Lewin, K. (1958). Group decisions and social change. Readings in Social Psychology. T. M. N. G.E. Swanson, \& E.L. Hartley,. New York, Holt, Reinhart \& Winston. : 459-473.

Lewis, P.A., Mai, V.A.T., Gray, G. (2011) (in press). Bilingual asynchronous online discussion groups: design and delivery of an elearning distance study module for nurse academics in a developing country. Nurse Education Today

McGill , I. and A. Brockbank (2004). The action learning handbook: powerful techniques for education, professional development and training. London, Routledge Falmer ;Taylor \& Francis.

Muc, P. D. (2009 ). "Vietnam ".

Piercy , N. and W. Giles (1989). "Making SWOT Analysis Work." Marketing Intelligence \& Planning 7 ( 5/6): 5 - 7. 
Pron, A. L., D. Zygmont, et al. (2008). "Educating the educators at Hue Medical College, Hue, Viet Nam." International Nursing Review 55(2): 212 218.

Steiner, Y. and L. Snell (1999). "Interactive lecturing: strategies for increasing participation in large group presentations." Medical Teacher 21(1): 37-42.

Stockhausen, L. J. (2007). "Developing culturally competent reflective practitioners. Part 1. Cultural reflections." Asian Journal of Nursing 10(4): 212-217.

Van, H. N., H. N. V. Quoc, et al. (2010). "Continuing medical education in Vietnam: new legislation and new roles for medical schools." Journal of Continuing Education in the Health Professions 30(2): 144-148.

WHO (2007). Module :5 Managing communication and the change management. Health Service Planning and Policy-making-A toolkit for nurses and midwives, WHO Western Pacific Region.

Xuan Do Dinh (2010). "Healthcare and development in Vietnam." Diversity in Health and Care 7: $9-11$. 
